\title{
Dynamics simulation of mechanical gearbox vibration
}

\author{
Jan Furch ${ }^{1, *}$, and Cao Vu Tran ${ }^{1}$ \\ ${ }^{1}$ University of Defence, Faculty of Military Technology, Kounicova 65, 66210 Brno, Czech Republic
}

\begin{abstract}
This paper focuses on creating a virtual model of mechanical gearbox used in medium-sized terrain vehicle using MSC.Adams software. This software is regarded as the most common and effective tool to simulate the gearbox as multibody system and to record and analyse the vibration signal from the gearbox. The paper makes an overview of modelling and simulation and performs an analysis with frequency spectrum. The paper demonstrates that it is possible to simulate vibration signals through the model of the gearbox created in 3D CAD software and then analyse in multi-body dynamics software MSC.Adams. Successful application of the virtual model not only help us decrease the cost of design work, but also help us identify the patterns of the vibration signal and the relations between the signal and the technical condition of the gearbox. The goal is to create a virtual model of a mechanical gearbox. In MSC.Adams, the vibration values of the rotating components can be detected in different gears. These values are then analysed and evaluated. The result is a simulation of fault states and identification of vibration frequencies for practical applications.
\end{abstract}

\section{Introduction}

The mechanical gearbox is the basic part of all mechanical machines. In a vehicle it is one of the most important elements which enables torque to be transferred from the combustion engine to the final gears of single driving axles.

The vibrations of the gear box are transferred by the joints of single shafts. Vibrations occur because of the rotation of an input shaft followed by tooth wheel meshing, and also because of the single bearings placement. That is the reason why strokes are made depending on revolutions and load which stimulate natural vibration signals in a gear box. The operation of the gear box, which is time-dependent, results in the wear of machine parts and failure [1]. Our aim is to design a gear box by modelling so that no critical vibration spectrum would occur and the presumed service life would be preserved. Another important aspect we are going to deal with is the observation of a vibration signal during the gear box service life. In practice it is essential to determine a critical vibration signal which would help to prevent failure occurrence. For this purpose we can use a virtual model which enables us to examine a vibration signal at low cost [2]. The aim is to decide how detailed the model should be to correctly describe the vibrational and acoustic performance of the powertrain [3].

The development of computer technology and software in the area of modelling is quite advanced nowadays, therefore we used modern software MSC.Adams for modelling the mechanical gearbox vibrations as it seems to be the best [4].

\section{Theory of modelling of mechanical gearbox vibrations}

In practice the aim of modelling is to understand the observed phenomena, imitate the behaviour of the examined system, simulate it on the model and then impact its behaviour in a required way, e.g. by its observed inner states. The model is only an approximation of reality since the real system can be very complex and the model might not fit the system completely. Therefore, we perform verifying experiments which enable us to complete and improve the model parameters or the model itself [5].

Modelling and simulation are the activities connected with making models of real world objects and experimenting with these models.

MSC.Adams (Automatic Dynamic Analysis of Mechanical System) is computing software used for modelling, analysing and optimizing mechanical systems called MBS (Multi-Body System). It supports static, kinematic, and dynamic analyses of the model. In other words, this software is based on a physical model describing the model specifically by relevant ideal objects (mass, rotational inertia, length, kinds of joints, etc.) [6].

MSC. Adams consists of a number of different modules, e.g. Adams/View, Adams/Car, Adams/Chassis, Adams/Driveline, etc. For modelling gear box vibrations and analysing the results we have used a universal module MSC.Adams/View [6].

The mechanical gearbox model has numerous parts. A basic part is the gear box where an input, output and counter shaft are placed. These shafts are supplemented by tooth wheels and bearing structures. In order to

\footnotetext{
*orresponding author: jan.furch@,unob.cz
} 
describe the gearing box, the input, output and counter shaft more accurately we have chosen program Inventor 2014 (software 3D-CAD), which can be seen in Fig. 1. Then it is exported to MSC.Adams. For the tooth wheels and the bearing structures we have used module MSC. Adams/View.
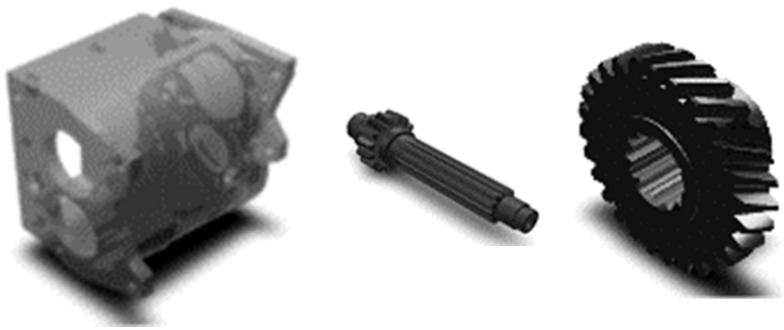

Fig. 1. Gearing box, the input, output and tooth wheel in program Inventor 2014.

The basic steps in modelling and simulating in the MSC.Adams/View module are as follows:

- create models and bodies - geometrical shapes (length, width, depth, dimension, distance among shafts, etc.),

- put physical characteristics - rotational inertia, mass, dynamic friction coefficient, etc.,

- create structures - kinematics definition (translation, rotation, calm, etc.),

- run a simulation - make motion forces, observe model behaviour,

- record and analyse results in MSC.Adams/ Postprocessing [4], [7].

\subsection{Description of the creation of a body model}

The mechanical gearbox of vehicle consists of three shafts and five speed gears with the following gear ratios for single speed gears $-1^{\text {st }}$ speed gear $-4,124 ; 2^{\text {nd }}$ speed gear $-2,641$; $3^{\text {rd }}$ speed gear $-1,58 ; 4^{\text {th }}$ speed gear $-1,00$; reverse movement - 5,224).

The shafts and the gear box were created in the Inventor environment in the 3D-CAD module to have accurate dimensions, construction, shapes, and rotational inertias. After that the values were transported to the MSC. Adams environment of the module View where the rest of the parameters were modelled according to the following parameters, see Tables 1 and 2 .

The bearing between a propelling shaft and a driven shaft was modelled according to the following information. In the bearing there are 14 rollers and the diameter of the rollers is $5,51 \mathrm{~mm}$. The rotational inertia of the tooth wheels was calculated in the Inventor environment as [8]:

$$
\begin{gathered}
I_{x x}=\frac{1}{2} m r^{2} ; \\
I_{y y}=\frac{1}{12} m\left(3 r^{2}+L^{2}\right),
\end{gathered}
$$

where: $m$ - mass of the tooth wheel, $r$ - radius of the tooth wheel, $L$ - width of the tooth wheel, $\mathrm{xx}$ - rotating axis, yy, $\mathrm{ZZ}$ - perpendicular axes with rotating axis (Fig. 2).

The values of the selected variables are given in Table 4. The adjustment of the remaining two variables such as the contact exponent and the damping distance was left unchanged.

Table 1. Basic geometrical data of tooth wheels of the mechanical gearbox of a vehicle.

\begin{tabular}{|c|c|c|c|c|}
\hline $\begin{array}{c}\text { Table Name of } \\
\text { the part }\end{array}$ & $\begin{array}{c}\text { Module } \\
\text { (mm) }\end{array}$ & $\begin{array}{c}\text { Number } \\
\text { of teeth }\end{array}$ & $\begin{array}{c}\text { Width of } \\
\text { teeth (mm) }\end{array}$ & $\begin{array}{c}\text { Type of } \\
\text { teeth }\end{array}$ \\
\hline $\begin{array}{c}\text { Drive gear of an } \\
\text { axle drive } \\
\text { reduction }\end{array}$ & 3 & 15 & 20 & rectilinear \\
\hline $\begin{array}{c}\text { Driven gear of } \\
\text { an axle drive } \\
\text { reduction }\end{array}$ & 3 & 32 & 20 & rectilinear \\
\hline $\begin{array}{c}\text { Drive gear third } \\
\text { speed }\end{array}$ & 3 & 27 & 20 & spiral \\
\hline $\begin{array}{c}\text { Driven gear third } \\
\text { speed }\end{array}$ & 3 & 20 & 20 & spiral \\
\hline $\begin{array}{c}\text { Drive gear } \\
\text { second speed }\end{array}$ & 3 & 21 & 21 & spiral \\
\hline $\begin{array}{c}\text { Driven gear } \\
\text { second speed }\end{array}$ & 3 & 26 & 21 & spiral \\
\hline $\begin{array}{c}\text { Drive gear first } \\
\text { speed }\end{array}$ & 3,5 & 15 & 20 & rectilinear \\
\hline $\begin{array}{c}\text { Driven gear first } \\
\text { speed }\end{array}$ & 3,5 & 29 & 20 & rectilinear \\
\hline $\begin{array}{c}\text { Driven gear of a } \\
\text { reverse } \\
\text { movement }\end{array}$ & 3,5 & 19 & 13 & rectilinear \\
\hline $\begin{array}{c}\text { Drive gear of a } \\
\text { reverse } \\
\text { movement }\end{array}$ & 3,5 & 15 & 13 & rectilinear \\
\hline
\end{tabular}

Table 2. Name of bearing.

\begin{tabular}{|c|c|}
\hline Table Name of the Bearings & Numbers \\
\hline Input shaft bearings & SKF 6208 \\
\hline Countershaft bearings & SKF 6305 + SKF 6306 \\
\hline Output shaft bearings & SKF BS2-2207-2CS \\
\hline
\end{tabular}

Table 3. Calculated rotational inertias in the Inventor

\begin{tabular}{|c|c|c|c|c|}
\hline Name of the part & $\begin{array}{c}\text { Mass } \\
(\mathrm{kg})\end{array}$ & $\begin{array}{c}I_{x x} \\
\left(\mathrm{~kg} \cdot \mathrm{mm}^{-2}\right)\end{array}$ & \begin{tabular}{|c|}
$I_{y y}$ \\
$\left(\mathrm{~kg} \cdot \mathrm{mm}^{-2}\right)$ \\
\end{tabular} & $\begin{array}{c}I_{z z} \\
\left(\mathrm{~kg} \cdot \mathrm{mm}^{-2}\right)\end{array}$ \\
\hline $\begin{array}{l}\text { Driven gear of an } \\
\text { axle drive reduction }\end{array}$ & 1,181 & 1849,805 & 1173,785 & 1173,785 \\
\hline $\begin{array}{c}\text { Drive gear third } \\
\text { speed }\end{array}$ & 1,134 & 1203,801 & 722,55 & 722,55 \\
\hline $\begin{array}{l}\text { Driven gear third } \\
\text { speed }\end{array}$ & 0,696 & 459,411 & 306,872 & 306,872 \\
\hline $\begin{array}{c}\text { Drive gear second } \\
\text { speed }\end{array}$ & 0,502 & 398,682 & 216,189 & 216,189 \\
\hline $\begin{array}{c}\text { Driven gear second } \\
\text { speed }\end{array}$ & 0,826 & 981,071 & 533,479 & 533,479 \\
\hline $\begin{array}{c}\text { Driven gear first } \\
\text { speed }\end{array}$ & 1,15 & 1993,909 & 1077,648 & 1077,648 \\
\hline $\begin{array}{c}\text { Reverse movement } \\
\text { wheels }\end{array}$ & 0,684 & 466,87 & 337,549 & 337,549 \\
\hline
\end{tabular}
environment.

Table 4. Variables necessary for defining the contact of the gearing [7].

\begin{tabular}{|c|c|}
\hline Variables & Values \\
\hline Static friction coefficient $\left(\mu_{\mathrm{s}}\right)$ & 0,1 \\
\hline Static transonic speed $\left(\mathrm{v}_{\mathrm{s}}\right)$ & $1(\mathrm{~mm} / \mathrm{s})$ \\
\hline Dynamic friction coefficient $\left(\mu_{\mathrm{d}}\right)$ & 0,08 \\
\hline Dynamic transonic speed $\left(\mathrm{v}_{\mathrm{d}}\right)$ & $10(\mathrm{~mm} / \mathrm{s})$ \\
\hline
\end{tabular}




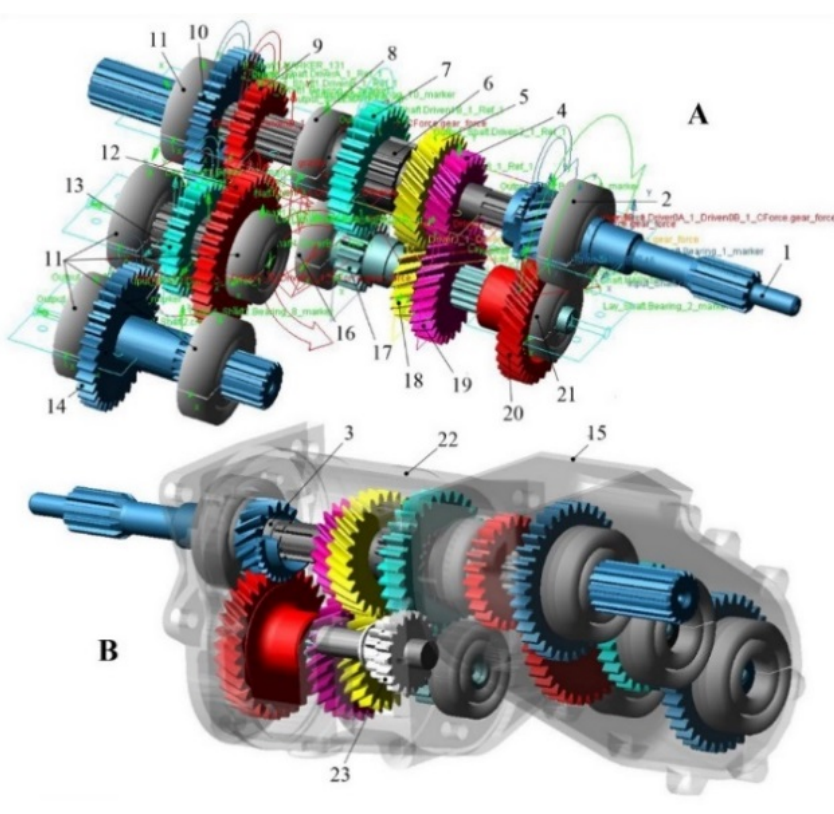

Fig. 2. Virtual model of the mechanical gear box of a vehicle $[7,9]$. A - Model with all constraints; B-Model with all cases.

1 - Input shaft with constant-mesh drive gear;

2 - Single row deep groove ball bearing SKF 6208;

3 - Roller bearing SKF NU 2204 between the input shaft 1 and the output shaft 6 ;

$4-3^{\text {rd }}$ speed driven gear;

$5-2^{\text {nd }}$ speed driven gear;

6 - Output shaft of gearbox;

$7-1^{\text {st }}$ speed driven gear;

8 - Double row angular contact ball bearing SKF 3207BN;

9 - Rear axle and underdrive engaging gear;

10 - Rear axle drive shaft with gear;

11 - Single row deep groove ball bearing SKF 6307;

12 - Layshaft of transfer box with idle gear;

13 - Front axle drive gear;

14 - Front axle drive shaft with gear;

15 - Transfer gearbox case;

16 - Single row deep groove ball bearing SKF 6306;

17 - Layshaft (or countershaft) with $1^{\text {st }}$ speed drive gear;

$18-2^{\text {nd }}$ speed drive gear;

$19-3^{\text {rd }}$ speed driver gear;

20 - Constant-mesh driven gear;

21 - Single row deep groove ball bearing SKF 6305;

22 - Gearbox case;

23 - Reverse gears

\subsection{Description of the creation of the joints}

The operation of transmission gearings and synchronizer clutches of a real gear box are simulated in the virtual model by joints. The first assumption is that the tooth wheels are fastened on the countershaft with the shaft designated as a "fixed joint". The second assumption is that the tooth wheels are not loaded on the driven shift in the idle position and are fastened only if the speed is engaged. Three shafts in relation to each other are placed by rotation joints designated as "Revolute joint". Single shafts are places in ball-bearings which are connected with the box of the transmission. It enables the vibration signal to be transmitted through these bearings to the gear box (Fig. 2).

\subsection{Description of simulation}

It is a special process performed in MSC.Adams/View [6] module during which the mechanical gear box of the vehicle is replaced by its model. The aim of this process is to obtain the information about the examined dynamic system and find whether the model is designed properly and whether its behaviour corresponds to reality. To put it simply, simulation is a process during which a virtual gear box model is created. It resembles a real gear box with the properties observed during the operation. In our case this is the simulation of vibrations.

Generally, vibrations consist of vibration signals in three axes $-x, y$ and $z$. The basic parameters which are calculated for vibrations are trajectory, velocity and angular velocity, acceleration and angular acceleration [10]. All these aspects are simulated and then analysed in the MSC.Adams/Postprocessor module.

The gearbox is used to transfer the engine power and the moment to the axles of the vehicle. In the process of operation it could suffer from heavy stimulation of the engine, the axles, the clutch and other resources such as oil, backlash, and clearance. The stimulation makes the changes of the dynamic load very complex which is the main reason for vibrations, impact, noise and other signs. The selected operating conditions are based on the working characteristics of the gearbox in the field and they are among the huge number of possible choices which can be applied to the virtual gearbox:

a) Rotation speed $n=1500 \mathrm{rpm}$ is applied on the input shaft (Fig. 2, position 1);

b) A position of $3 \mathrm{rd}$ speed gear $(i=1,58)$ is chosen in the gearbox and two-wheel-drive mode is chosen in the transfer box;

c) The load torque can be calculated from the maximum torque of the engine used on the vehicle $(166,7 \mathrm{Nm})$ and the respective ratio $(i=1,58)$, then the load torques of $263,386 \mathrm{Nm}$ is applied on the output shaft (Fig. 2, position 6);

d) Other parameters are applied as follows:

- simulation time (end time) $1 \mathrm{~s}$,

- simulation step (step size) 0,0001 s.

\section{Analysis of the simulation results}

\subsection{Algorithms for the dynamic simulation}

MSC.Adams offers four solvers (the Gstiff, Wstiff, Dstiff and Constant-BDF) to solve the Differential-Algebra Equation (DAE) for the multi-body dynamic simulation. All of them use multi-step, variable order algorithms and apply one of these three integration formats including the Index3 (I3), Stabilized Index 1 (SI1) and Stabilized Index 2 (SI2) [4].

The Gstiff and the Wstiff use a variable step and fixed coefficients. The former helps us to calculate faster and with higher accuracy, but when computing velocity, they can make an error which might excite discontinuities in acceleration. Because of this, the error must be controlled by limiting the maximum step during the simulation. The latter is more useful and stable because it could be 
modified according to variable steps without any accuracy loss, but it requires more calculated time than those by the Gstiff. The Dstiff algorithm is similar to the Wstiff, but it allows us to choose only the integration format Index3. Unlike them, the Constant-BDF algorithm uses fixed steps, so it is very useful when SI2 format is selected with short step. Although it does not calculate as fast as the Gstiff and Wstiff, it also reaches high accuracy and it is not as sensitive to the discontinuity of the acceleration and force as the Gstiff [4].

Integration formats differ a lot, for instance the SI3 monitors only the error of the displacement and other state variables of the differential equations, but not the velocities and constrained reaction forces. Therefore, its accuracy when calculating velocities, acceleration and constrained reaction forces is not as high as that of the others. The SI1 can monitor all state variables such as displacement, velocity and Lagrange multiplier by introducing the velocity constrained equations instead of acceleration constrained equations. Therefore, it calculates quite accurately but it is very sensitive to the models with friction and contact problems. Unlike the SI1, the SI2 is able to control the errors of the Lagrange multiplier and velocity by considering the velocity constrained equations, so more accurate result could be obtained for the velocity and acceleration computation.

Based on the above information about the solvers and integration formats, the Wstiff solver with SI2 integration is adopted for the dynamic simulation of the gearbox [4].

\subsection{Algorithms analysing the contact force}

Because the function of contact force is periodic, a Fourier transform (FFT) will be used to decompose it into a sum of simple harmonic functions, namely sines and cosines. Theoretically, the FFT can be defined as follows [11]:

$$
x(t)=a_{0}+\sum_{n=1}^{\infty}\left(a_{n} \cos \frac{2 n \pi t}{T}+b_{n} \sin \frac{2 n \pi t}{T}\right),
$$

where $x(t)$ is the function of contact force with period $T$, $a_{n}$ and $b_{n}$ are constants called the coefficients of the transform and given by the Euler formulas [11]:

$$
\begin{gathered}
a_{0}=\frac{1}{T} \int_{-T / 2}^{T / 2} x(t) d t \\
a_{\mathrm{n}}=\frac{2}{T} \int_{-T / 2}^{T / 2} x(t) \cos \frac{2 \pi n t}{T} d t, n=1,2, \ldots ; \\
b_{\mathrm{n}}=\frac{2}{T} \int_{-T / 2}^{T / 2} x(t) \sin \frac{2 \pi n t}{T} d t, n=1,2, \ldots
\end{gathered}
$$

However, in practice, the function of contact force is a set of data with discrete and finite values $x_{n}(n=1,2, \ldots)$. To perform the analysis using these finite values of discrete data, the discrete Fourier transform (DFT) should be applied [11]:

$X_{n}=\frac{1}{N} \sum_{k=0}^{N-1} x_{k} e^{-j 2 \pi n k / N} n m=0,2,2, \ldots N-1$,

where $N$ is the number of $x_{n}$ in a constant interval $\Delta t$ and $X_{n}$ is called DFT of the discrete values $x_{0}, x_{1} \ldots x_{N-1}$.
Equation (8) will transfer correspondingly finite values on the time axis to the discrete spectra on the frequency axis. DFT can also use real numbers instead of complex ones [11]:

$$
\left\{\begin{array}{l}
A_{n}=\frac{1}{N} \sum_{k=0}^{N-1} x_{k} \cos \frac{2 \pi n k}{N} \\
B_{n}=\frac{1}{N} \sum_{k=0}^{N-1} x_{k} \sin \frac{2 \pi n k}{N}
\end{array} \mathrm{n}=0,1,2, \ldots \mathrm{N}-1,\right.
$$

where $X_{n}=A_{n}+j B_{n}$.

We apply a window function in the work in order to provide the discrete values that appear to be continuous and periodic. Discontinuities are "filled in" by forcing the function of contact force to be equal to zero at the beginning and the end of the calculated period.

There are many available windowing functions such as Rectangular (it is equivalent to saying that no window was used), Gaussian, Hamming, Blackman-Harris and Hanning.

$$
w[n]=0,723-0,498 \cos \frac{2 \pi n}{N}+0,0792 \cos \frac{4 \pi n}{N}
$$

After many trial calculations, Blackman-Harris windowing function was chosen to be used in this work.

\section{Results and discussion}

\subsection{Gear mesh frequencies (GMF)}

The gear mesh frequency also called "tooth mesh frequency" is the rate at which gear teeth mesh together in a gearbox. It is equal to the number of teeth on the gear times the rotation speed of the gear [8]

$$
f_{m}=f Z,
$$

where $f_{m}$ is the gear mesh frequency $(\mathrm{Hz}), f$ is rotational frequency of the gear $(\mathrm{Hz})$ and $Z$ is the number of teeth.

The number of teeth on the drive gear multiplied by the speed of the drive gear must equal the number of teeth on the driven gear times the speed of the driven gear. As the pinion rotates against the driven gear, the individual cycles of the frequency generated are a profile of the individual teeth meshing. Gear mesh frequencies of gears in the gearbox were calculated as follows (see Table 5):

Table 5. The GMF in 3rd speed gear, two-wheel-drive mode and $1500 \mathrm{rpm}$ on the input shaft [7].

\begin{tabular}{|c|c|c|c|}
\hline Description & Gear & $\begin{array}{c}\text { Number of } \\
\text { teeth }\end{array}$ & Values (Hz) \\
\hline \multirow{2}{*}{$\begin{array}{c}\text { The constant- } \\
\text { mesh gears }\end{array}$} & Drive gear & $Z_{0 R}=15$ & \multirow{2}{*}{$f_{m 0}=375$} \\
\cline { 2 - 3 } & Driven gear & $Z_{0 N}=32$ & \\
\hline \multirow{2}{*}{ 1st speed gear } & Drive gear & $Z_{1 R}=15$ & \multirow{2}{*}{$f_{m 1}=175,78$} \\
\cline { 2 - 3 } & Driven gear & $Z_{1 N}=29$ & \\
\hline \multirow{2}{*}{ 2nd speed gear } & Drive gear & $Z_{2 R}=21$ & \multirow{2}{*}{$f_{m 2}=246,094$} \\
\cline { 2 - 3 } & Driven gear & $Z_{2 N}=26$ & \\
\hline \multirow{2}{*}{ 3rd speed gear } & Drive gear & $Z_{3 R}=27$ & \multirow{2}{*}{$f_{m 3}=316,406$} \\
\cline { 2 - 3 } & Driven gear & $Z_{3 N}=20$ & \\
\hline
\end{tabular}




\subsection{Impact of input revolution on the vibrational signal}

In order to analyse the dependence of a vibration signal on the number of revolutions we selected only three input shaft revolutions $\left(1000,2000\right.$ and $\left.3000 \mathrm{rpm}^{-1}\right)$ shifting into second gear. This number of results is adequate for expressing the dependence. In order to express the simulation results we chose the acceleration values in vertical axis $y$ which is perpendicular to the axis of mechanical gear box rotation (Fig. 3).

On the basis of the above results (Fig. 3) we can hypothesize that the higher the input shaft revolutions, the higher the amplitude in the frequency spectrum. This specific trend is probably the result of the assumption that the higher the number of input shaft revolutions, the higher the gear box oscillation. This analysis proves that higher revolutions of parts result in higher operation wear and later in failure occurrence.

\subsection{Impact of shifting speed gear on vibrational signal}

In order to verify the impact of shifting single speed gears on the vibration signal we selected $2000 \mathrm{rpm}^{-1}$ on the input shaft (Fig. 4). The graphs showing single speed gears designated as CW1 for first gear up to CW4 for fourth gear present the difference in a vibration signal. Since the tooth wheels have different number of cogs, when connected together on the input shaft, countershaft and output shaft, they cause the difference in the vibration signal. The biggest difference in the vibration signal is at fourth speed gear because of the direct connection of the input and the output shaft. The frequency spectrum at first, second and third speed gear is similar since the countershaft and its tooth wheels are in contact.

\subsection{Impact of gear box construction on vibrational signal}

The vibration signal is influenced by the number of teeth, shafts and their positioning. In this chapter we selected two possible types of bearings and the direction of the gearing pair of first gear. In another step we simulated the change of the ball-bearing SKF 6305/6306 (6 balls) on the countershaft into the ball-bearing SKF 6305/6306 ETN9 (5 balls) (Fig. 5). The figure shows that the smaller the number of bearing balls, the higher the oscillation amplitude of a gear box.

\subsection{Example of an experimental mechanical vibration measurement of the mechanical gearbox}

In order to verify the impact of the damaged outer ring on the vibration signal of the tested roller bearing, the outer ring was artificially damaged. We cut a groove parallel to the axis of rotation and perpendicular to the track of rolling elements, see Fig. 6. For the experimental analysis, we selected the measurement at 1200 RPM of the shaft [12].

Table 6 shows the calculation results of the frequencies of typical bearing failures for the shaft revolving at 1200 RPM. The value of $B P F O$ corresponds to the result of the frequency analysis, which is given in the upper right hand corner in Fig. 7. Small errors may be caused by the inaccurate measurement of bearing shaft revolutions. Fig. 7 was created after using the envelope detection which, on the basis of a band-elimination filter, enables us to filter the lower and upper undesirable vibrations which may have a negative impact on the envelope detection analysis [12].
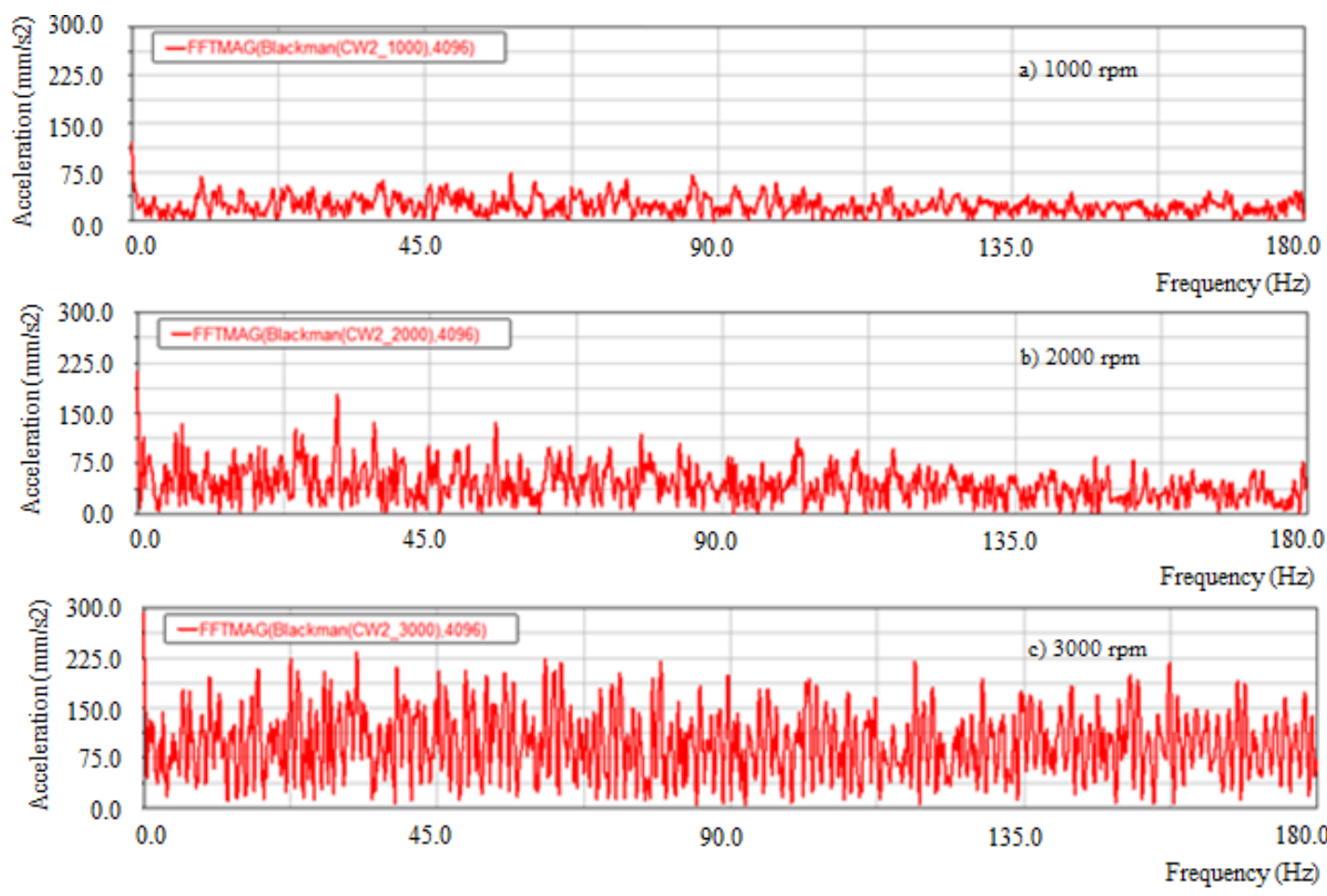

Fig. 3. Record of a frequency spectrum by the number of revolutions, Gearbox UAZ469. 

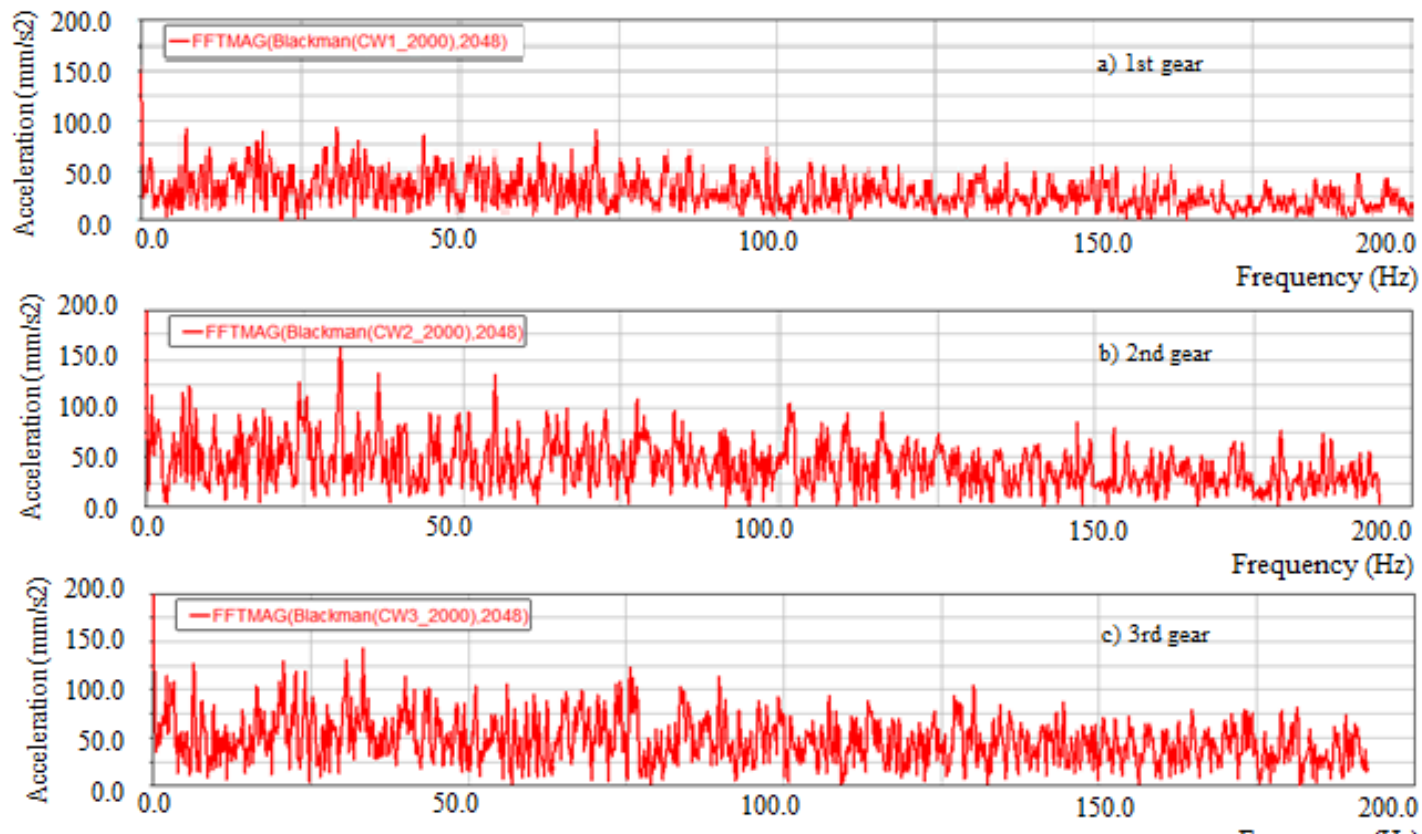

Frequency $(\mathrm{Hz})$

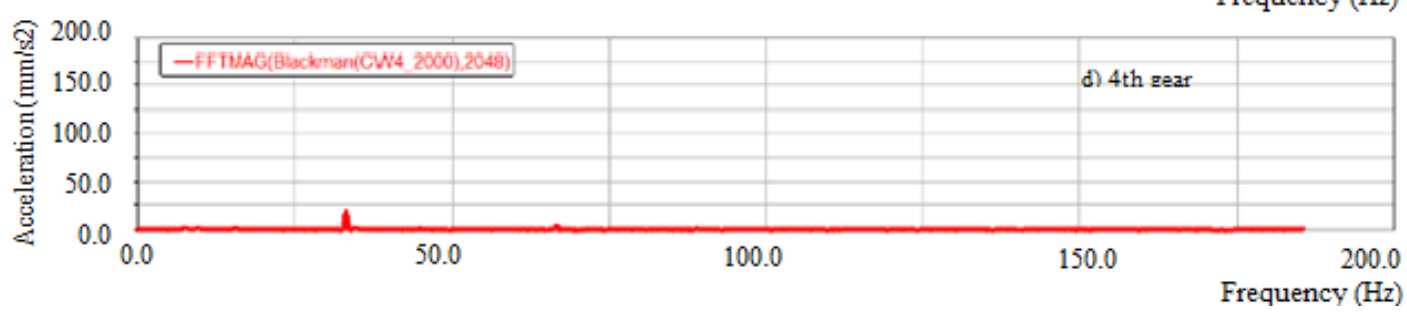

Fig. 4. Frequency spectrum record based on shifting a speed gear, Gearbox UAZ469.
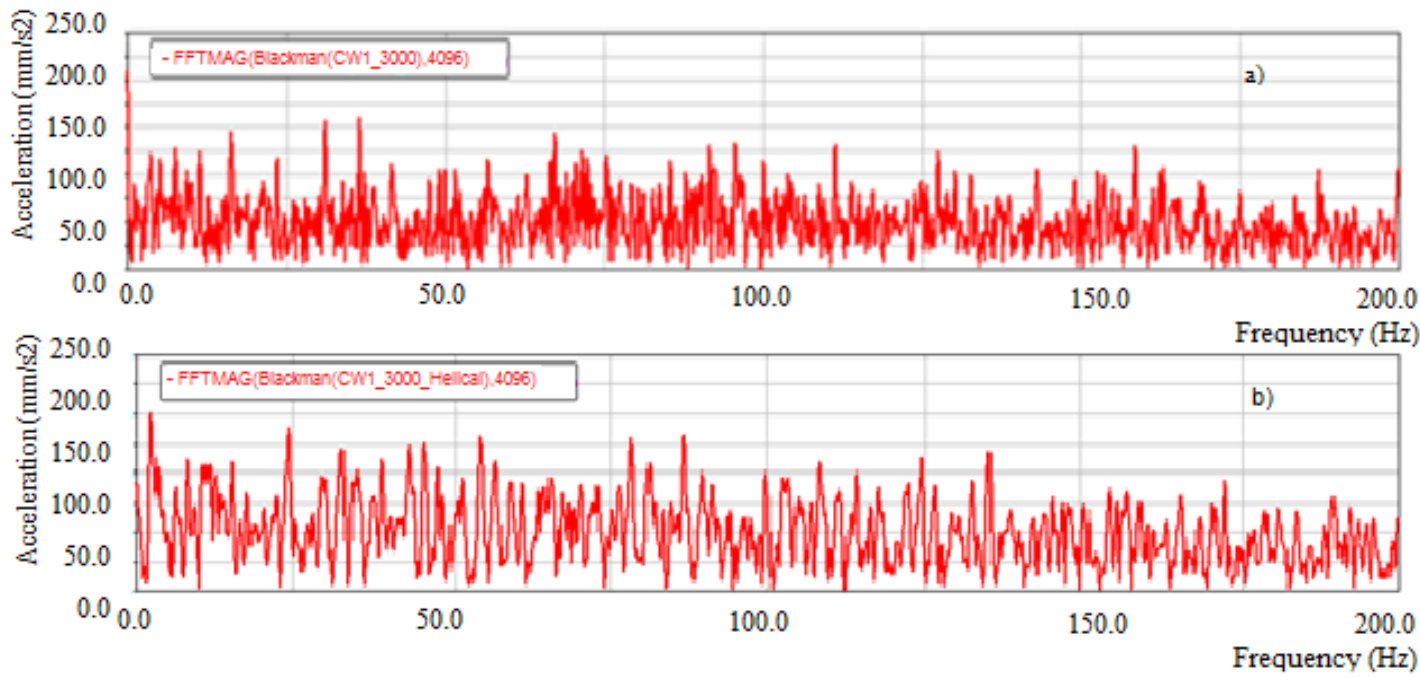

Fig. 5. Frequency spectrum record after the change of a ball-bearing on a countershaft: a) ball-bearing SKF 6305/6306 (6 balls), b) ball-bearing SKF 6305/6306 ETN9 (5 balls).

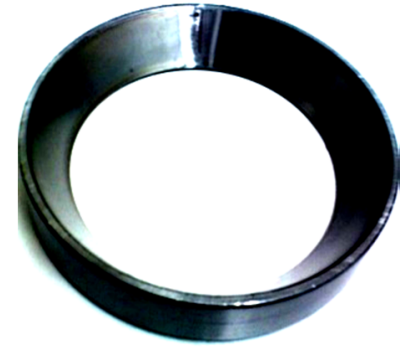

Table 6. The values calculated for bearing fault frequencies labelled FAG 31308A [12].

\begin{tabular}{|c|c|}
\hline Designations of fault frequency & $\boldsymbol{f}_{\boldsymbol{r}}$ frequency $\mathbf{2 0 ~} \mathbf{~ H z}$ \\
\hline Snap ring defect $-F T F$ & 8,42 \\
\hline Bearing defect $-B P F$ & 107,22 \\
\hline Outer race $-B P F O$ & 136,64 \\
\hline Inner race $-B P F I$ & 185,36 \\
\hline
\end{tabular}

Fig. 6. A groove created on the outer ring [12]. 


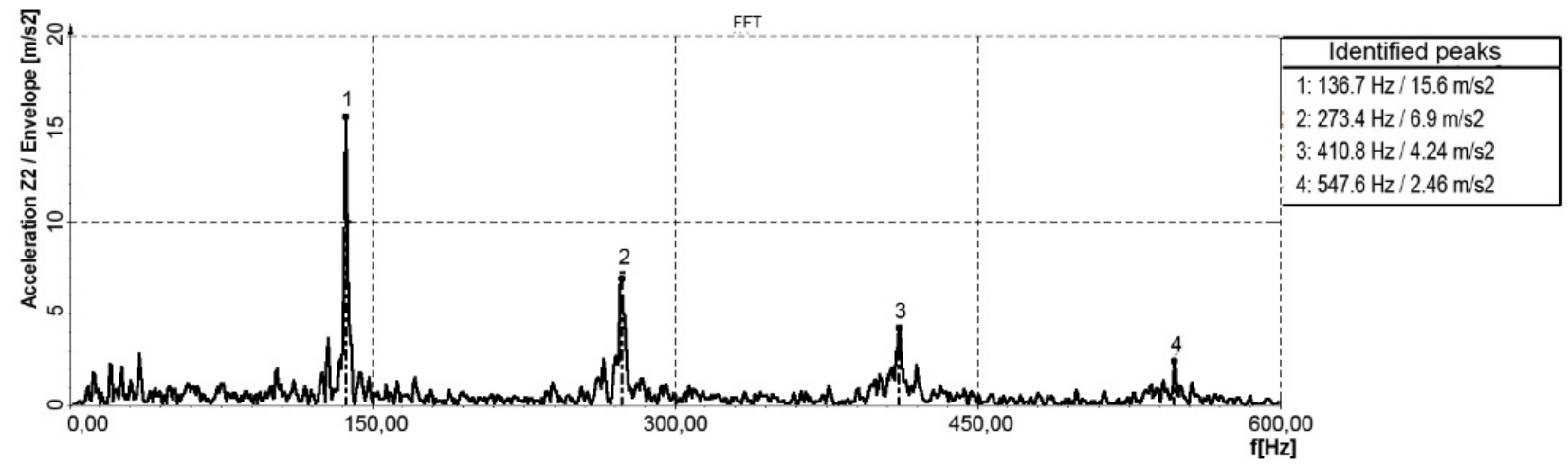

Fig. 7. The frequency spectrum of the damaged outer ring obtained by means of envelope detection [12].

\section{Conclusion}

The aim of the paper is to establish whether it is possible to simulate vibrodiagnostic signal to monitor the technical condition of rotating components in a mechanical gearbox, which is one of the most important elements in a combat vehicle. On the basis of the process we can state that the vibration signal is a very effective tool when tracking the technical condition of the mechanical gearbox. In the process of modelling, it is important to solve some problems such as creating accurate bodies, determining physical values (mass, rotational inertia, etc.), creating proper motions, setting software for simulation, presenting the simulation results. For modelling and simulation we have used the software of ADAMS/View of the MSC company, which seems to be the most suitable. Together with the MSC Adams/View module, we have used the Inventor software of the Autodesk company for building bodies and determining their physical values. This software enables the bodies to be created more accurately. Next, the virtual bodies were transformed into the MSC Adams/View software where they were simulated and the frequency spectra were recorded. This software was used to make some changes in the mechanical gearbox structure influencing the vibration. Simulations are an effective tool for making different designs which are difficult to make in practice. We established the impact of the different design modifications on the vibration signal which can help us to monitor the technical condition and predict failure in the future.

The present work has been prepared with the support of the Ministry of Defence of the Czech Republic, Partial Project for Institutional Development and Specific Research, Department of Combat and Special Vehicles, University of Defence, Brno.

\section{References}

1. D. $\mathrm{Wu}, \mathrm{J}$. Meagher, C. Xu, Nonlinear contact analysis of gear teeth for malfunction diagnostics, IMAC XXVI Conference and Exposition on Structural Dynamics (2008)
2. Q. Wilson, I. Fatimah, G. Farid, Assessment of gear damage monitoring techniques using vibration measurements, Mechanical Systems and Signal Processing, 15(5), 905-922 (2001)

3. P. Novotný, A. Prokop, M. Zubík, K. Řehák, Investigating the impact of computational model complexity on noise and vibration modeling of powertrain, Journal of Vibroengineering, 22(4), 277392 (2016)

4. Mechanical dynamics. Building Models in ADAMS/View (Michigan, Ann Arbor, 2000)

5. X. Wu, A. Sommer, J. Meagher, Spectrum Diagnostics of a Damaged Differential Planetary Gear during Various Operating Conditions, Physical Science International Journal, 9(3), 1-13 (2016)

6. Adams team at MSC Software. Adams tutorial kit for mechanical engineering courses, (Newport Beach, CA, 2003)

7. J. Furch, T. T. Nguyen, Simulation of Failure in Gearbox Using MSC.ADAMS, Acta Universitatis Agriculturae et Silviculturae Mendelianae Brunensis, 65(2), 419-428, (2017)

8. M. Norton, D. Karczub, Fundamentals of Noise and Vibration Analysis for Engineers, 2nd ed. (Cambridge, Cambridge University Press, 2003)

9. J. Furch, J. Glos, T. T. Nguyen, Modelling and simulation of mechanical gearbox vibrations, International scientific conference Transport means, 133-139 (2016)

10. D. Hroncová, M. Binda, P. Šarga, F. Kičák, Kinematical Analysis of Crank Slider Mechanism Using MSC Adams/View. Procedia Engineering, 48, 213-222 (2012)

11. P. Bakir, Vibration based structural health monitoring, (Berlin, Technische Universität Berlin, 2008)

12. J. Furch, J. Glos, T. T. Nguyen, Identification of the Technical Condition of Roller Bearings by Means of Vibrodiagnostics and Tribodiagnostics. Transactions of FAMENA, 41(3), 99-113, (2017) 